DOI 10.5216/ia.v45i1.61125

\title{
¿PARA QUÉ SE EDUCA EN LA SOCIEDAD NEOLIBERAL?
}

\author{
JoRGE DÁVILA \\ Universidad de Los Andes (ULA), Mérida, Venezuela
}

\begin{abstract}
Resumo: Se busca responder la interrogante del título a través de varias maneras de entender lo que es la educación en una sociedad neoliberal. Luego se postula la hipótesis del sentido absolutamente destructivo del neoliberalismo en relación con el lenguaje en su forma más elemental. De allí se sugiere el sentido de una respuesta ante el peligro de ver realizada a cabalidad la aniquilación del lenguaje más elemental.
\end{abstract}

Palavras-chave: Interpretación. Lenguaje básico. Competencia. Alienación. Educación básica.

Ante esta pregunta, el lector tendrá ya al menos una respuesta. No tengo capacidad para imaginarlas todas. Quizás sea suficiente, para el propósito de este ensayo, tener en cuenta estas dos, tal vez no extrañas al lector, que a continuación expreso: 1) Quien tenga mirada condescendiente pensará que el objetivo de la educación en neoliberalismo es el de procurar desatar en el individuo las fuerzas creativas e innovadoras para la producción de riqueza; y ese objetivo es, a su vez, un medio, pues con esas fuerzas el individuo se asegura una vida buena. Capacitación y seguridad, se dirá desde esta mirada, son el medio y el fin, respectivamente, que la educación se propone desarrollar en el individuo. 2) Quien tenga una mirada desaprobadora, o más bien pesimista, pensará que el objetivo de la educación en la sociedad neoliberal es el de procurar sacar provecho máximo de la fuerza productiva del individuo, reducida a su carácter instrumental, para ponerla, sin resistencia del individuo, o más bien alienado él, al servicio del concentrado poder económico mundial. Instrumentalismo y alienación, se dirá desde esta mirada, son el medio y el fin, respectivamente, que la educación se propone desarrollar en el individuo.

Estas dos miradas parecen divergentes. Incluso se perciben como contrarias. Pero, iy si cada una de estas dos miradas fuese la de cada ojo mirando el mismo objeto? Donde el ojo derecho ve capacitación y seguridad, el ojo izquierdo ve instrumentalismo y alienación. Supongamos pues que ambas miradas se conjuntan; así, podemos preguntar: 1) ¿La mirada conjunta es disparatada? 2) ¿Acaso unidas ellas perfilan con mayor nitidez su objeto? 3) ¿Lo que ven en conjunto no alcanza sino en su superficie al objeto? Estas nuevas preguntas animan el razonamiento que busco exponer a continuación. 
Mi respuesta a la primera pregunta es que una mirada conjunta no resulta un disparate. Ciertamente son visiones muy distintas y de profundos fundamentos que las hacen rozar las fronteras de la contraposición, de ser polos opuestos. Resumo enseguida en qué consiste, esencialmente, cada una de esas visiones para poder afirmar que son visiones muy distintas; así podremos luego señalar qué puede resultar de la mirada conjunta.

Mirada del ojo derecho. Capacitarse para tener una vida segura. Esa expresión tiene su base de apoyo en la afirmación de un potencial de la condición humana y, al mismo tiempo, de un destino ideal para esa condición. El potencial de la condición humana consiste en la conjugación de potencias corporales y mentales tales que un ejercicio sistemático de experiencia en actividades coloca al individuo en condiciones de distinguirse en el medio en que se desenvuelve su vida. Esa distinción tiene como referencia lo que otros individuos hacen. Esa distinción es una afirmación comparativa del individuo en relación con lo que otros individuos, como él, buscan en la exacta dimensión en la que él mismo busca su distinción. Esa distinción se equipara con la competencia. Competir significa la incesante búsqueda de sobrepasar la capacidad que ya se tiene y, al mismo tiempo, superar la capacidad de los otros. Vivir en competencia, vivir para la competencia, vivir de los competidores, esta es la dimensión vital del individuo en la que se constituye el destino ideal de la condición humana. Ese destino ideal es el de la seguridad. Como resulta evidente es una seguridad no obtenida sino conquistada permanentemente. La vida en competencia es una vida segura en la exacta medida en que la competencia se realice sin punto de acabamiento. El sin cesar de la competencia es el núcleo esencial de la seguridad. Así, el fin inscrito en el destino de la condición humana, vivir en seguridad, no es perfectamente separable del medio de su realización, la afirmación del potencial de la condición humana como competencia. En este contexto, la tarea educativa, la misión de la formación de la población de menor experiencia en la vida, los niños y jóvenes, es la de procurar desatar en el individuo las fuerzas creativas e innovadoras para la competencia. Ahora bien, la manifestación concreta de esa competencia tiene que ser algo productivo. Productivo quiere decir: algo que mantenga en actividad la competencia, algo que permita la afirmación comparativa concreta entre individuos. Algo que, a su vez, sea soporte activo de la continuidad de la competencia. Algo que sea base común de la comparación. Ese algo no es otra cosa que la producción de riqueza. Con ella se tiene la medida común de la comparación entre individuos que compiten en el mismo medio; precisamente, el de la generación productiva de la riqueza. La educación, entonces, tiene una misión libertaria: preparar las mejores condiciones del individuo para que pueda desplegar todo su potencial de fuerzas creativas e innovadoras de la producción de riqueza.

Otra mirada, la del ojo izquierdo. La educación en el neoliberalismo es mero instrumentalismo que conduce a la alienación. Ese es el centro de la mirada que lo desaprueba. ¿En que se apoya su afirmación? Esta afirmación, que es una crítica al neoliberalismo expresada en términos negativos, se sostiene, en su fondo afirmativo, en la idea de que la condición humana guarda un potencial como fuerza productiva que no se limita a la producción de riqueza. La riqueza a la que está llamada la condición humana es tal 
DÁVILA, J.

que el individuo conjuga sus potencias corporales y mentales en un ejercicio sistemático de experiencia en actividades en las que su relación con otros individuos está signada por la convivencia en que se gesta la producción de una riqueza que es colectiva. Esa riqueza es, en su naturaleza, tanto la condición de posibilidad de las mismas potencias corporales y mentales del individuo como el fruto de esa posibilidad potencial. La potencia individual es tal sólo porque se expresa en el individuo, porque se manifiesta de manera concreta en él. No es él, el individuo, el poseedor real de su potencia, más bien es él la propia expresión de esa potencia. Esa potencia es, en su esencia, colectiva. Y de la expresión concreta de esa potencia colectiva en cada individuo resulta, en conjunto, algo más que la sencilla sumatoria o agregado de los frutos de esas expresiones; el resultado es el cambio de esa potencia en magnitud y cualidad. Aquí no se debe hablar de competencia sino más bien de 'con-potencia', si se permite el neologismo. El individuo es uno con y en la potencia colectiva. Así la riqueza no se limita al dominio individual de la competencia, puesto que la competencia queda subordinada a la primacía del esfuerzo por sostener aquella condición de posibilidad de las potencias individuales que no es otra cosa que el bien colectivo. Así, la competencia adquiere otro significado en el que la medida de ella está dada por el sostenimiento y el crecimiento del bien del conjunto social. Si ganadores hay en la competencia, entonces, esos son los que con más ímpetu contribuyen al bien del conjunto social. Sobre esta base, se entiende que la mirada reprobadora hacia el neoliberalismo, al que ve celebrar la competencia que enriquece el bien individual, entienda que él no puede proponerse otra cosa sino la consideración de la condición humana como un simple instrumento. Y así, la formación del individuo. Porque, entiende el trato de algo $(\mathrm{x})$ como instrumento a la condición en que ese algo $(\mathrm{x})$ es tomado fuera del todo $(X)$ al que pertenece para ponerlo al servicio de otro algo $(y)$ que pertenece $o$ no a ese todo $(X)$ del que forma parte aquél algo $(x)$. $Y$, como resulta evidente, si un $x$ del conjunto social es entendido y llevado a accionar fuera del conjunto $X-y$ por tanto no en beneficio ni de $X$ ni del mismo $x$ - entonces ese individuo $x$ está en condición de extrañamiento, está radicalmente alienado. Y cuanto más permanece $x$ en esa condición mayor será el grado de extrañamiento de su condición de pertenencia al conjunto social. Y si del mismo modo ocurre con muchos $X$, entonces será $X$ el que se convierta en un conjunto cada vez mayor en vaciedad. De esta manera la educación en el neoliberalismo es un proceso de destrucción de la condición básica de pertenencia que exige de suyo la condición humana, la condición de formación de un todo en el que se juega la vida de los integrantes de ese todo que no sería nada sin ellos y ellos nada sin él.

Ahora podemos abordar la interrogante de si es disparatada la conjunción de ambas miradas. Pero, ¿en verdad se pueden conjugar? Si las miradas se toman desde su fondo, ya lo decíamos, lucen casi contrarias. Una descansa en la idea de la condición humana como independiente de la adscripción de la persona a un conjunto social, mientras que la otra concibe una dependencia total. En otro nivel menos fundamental, una mirada ve la 'conformación neoliberal' como ajustada, o más bien céntrica, a su manera de entender la condición humana, mientras que la otra ve esa 'conformación neoliberal' como excéntrica a 
modo de entender la condición humana. Y, finalmente, último nivel, una concibe la misión educativa (la capacitación para la competencia) como acción necesaria para que la 'constelación ción neoliberal' se realice, mientras que la otra no señala nada afirmativo: sólo remite a la manera crítica en que observa, precisamente, lo que la otra mirada defiende en este último nivel; a saber, que la educación neoliberal conduce al perjuicio de lo más esencial de su manera de concebir la condición humana. Vale decir, en el último nivel, merced al trabajo crítico de la segunda mirada, se encuentra un punto de coincidencia en la observación: ambas miran el mismo objeto y mientras uno lo aprueba, lo afirma, la otra lo rechaza, lo desaprueba, lo niega. Así, podemos entender que no es disparatada una mirada conjunta mientras se entienda esa mirada conjunta como la reunión de dos lados de un mismo objeto. Pero ese objeto no está limitado a la mera misión y acción educativa. Con más amplitud, ambas miradas sí están de acuerdo en que observan el mismo fondo en que distinguen el objeto que llamamos misión de la educación. Ese fondo de distinción es, nada más y nada menos, el neoliberalismo. Y ese es el punto ciego de cada mirada y de la mirada conjunta. Ninguna hace explícita su respuesta a la pregunta por el neoliberalismo.

Con lo que venimos de decir, tenemos entonces cómo responder nuestras otras interrogantes: ¿Acaso unidas, o conjugadas, esas miradas perfilan con mayor nitidez su objeto? ¿Lo que ven en conjunto no alcanza sino en su superficie al objeto? El lector, esperamos, no tendrá dificultad en ver que sólo si a la mirada conjunta la entendiéramos como una suerte de juego dialéctico podríamos decir que se perfila con ella una mayor nitidez en el objeto de las miradas; obviamente si se concibe esa dialéctica como confrontación en el que llamamos último nivel: el de la misión educativa. Y así también el lector concederá que la respuesta a la otra pregunta tiene que ser afirmativa: la mirada conjunta se queda en la superficie. Por una doble razón. Por una parte, porque su punto firme de conjugación está precisamente en el nivel de la superficie, el de la misión educativa. Por otra parte, porque, como dijimos, el fondo del objeto que miran es un punto ciego para ambas, precisamente eso que llamamos conformación o constelación del neoliberalismo.

La mirada conjunta es limitada, especialmente en lo que concierne a su punto ciego. Pero tiene su virtud. Esa virtud radica en la dialéctica que se plantea entre ambas miradas. Esa dialéctica permite la riqueza de un debate del que hemos sido testigos durante décadas. Es el debate entre la posición de la educación emancipadora frente a la educación opresora; si, claro está, se ve dando primacía al ojo izquierdo. Es el debate entre la posición de la educación formadora de excelencia productiva frente a la educación parasitaria; si, claro está, se ve dando primacía al ojo derecho. Ese debate se nutre con mucho vigor de la confrontación entre las posturas relativas a la economía y a la política, preferentemente. Con menos vigor aparece en el debate el hilo de una confrontación que remita al fondo cultural. Es difícil no conceder que este debate ha tenido efectos transformadores en la conducción de los sistemas educativos en los países latinoamericanos. Ahora bien, cuando este debate se desenvuelve en su plenitud se distingue más claro el punto ciego de ambas miradas y de la mirada conjunta. Se entiende 
DÁVILA, J.

que se discute en el debate sobre la base de una comprensión del fenómeno del neoliberalismo, pero cuanto ocurre muestra que el acuerdo sobre tal comprensión sólo es en negativo; vale decir, el acuerdo es estrictamente nominal: es la designación cómoda de un fenómeno que escapa a los interlocutores y que sin embargo los reúne.

¿Y si al menos intentamos despejar las penumbras que deja el punto ciego? Ensayemos.

Algo que es palpable en la situación que hemos descrito sobre el debate dialéctico, lo postulamos así, es lo que puede definir en esencia al neoliberalismo. ¿Qué queremos decir? Se trata del fenómeno caracterizado por la confrontación de actores en la que los contrincantes se alejan cada vez más del objeto del debate convencidos, eso sí, de que están más cerca de él; más aún, que le es propio, en su aceptación o en su rechazo. Como el lector lo sabe, es la situación primigenia descrita en la antigüedad griega a propósito del juego de la retórica. En aquel entonces, el alerta que encendió el predominio de la sofística frente a la tradición hizo que el ejercicio de la razón tomara posición. Desde la razón, la retórica fue puesta al desnudo como un ejercicio confuso en el que la misma razón es asumida bajo la modalidad del simulacro. El arte de persuadir entró en confrontación con el arte de argumentar razonadamente. De por medio, el gran asombro de que esa faena se realiza en el lenguaje; un gran tema para la sofística y para la filosofía. La sofística llegará al extremo de postular que la palabra es creadora de realidad. Y si una realidad creada por el lenguaje se pretende explicar por el mismo lenguaje es tarea inútil. Basta, así, la designación nominal como punto básico para todo ardid de la pretensión de convencer, ora por la persuasión ora por el conocimiento racional. El ejercicio filosófico nace con otra pretensión al respecto. Se podría decir que, de modo más humilde, o menos arrogante, la primera solicitud, la primera petición de la Razón, en el ejercicio filosófico, es la de claridad en el lenguaje. Y, en simetría, su primera aversión es a la práctica de confundir en el lenguaje. De allí su empeño en lograr permanentemente la claridad de cuanto se afirma o se niega; de allí su empeño en hacer prevalecer la lógica que al tiempo que se estructura es capaz de decirse explícitamente a sí misma. Su choque frontal con la retórica es, naturalmente, un choque contra la tendencia a simular, a disfrazar; contra el simulacro como la forma preferida y predominante del ocultamiento -vale decir, de la negación de la verdad.

Ahora bien, vivimos el tiempo de la conformación o constelación del neoliberalismo. Con esta expresión queremos significar el predominio de una forma cultural que se expresa de manera muy clara en los dominios de lo político y de lo económico. Tal forma cultural es el modo de ser que manifiesta la cultura que se ha dado en llamar globalizada; es decir, esa que rebasa toda limitación de culturas particulares y, por ende, de modalidades de gobierno y de estructuras económicas. Postulamos aquí que algo muy de fondo caracteriza radicalmente ese modo de ser cultural y que concierne al lenguaje. Más limitadamente, lo que buscamos postular aquí es que vivimos el tiempo del predominio de un lenguaje que es algo más que na nueva retórica. El ejemplo explícito por excelencia de la vieja retórica está en Platón en quien se lee que la retórica no es más que el simulacro de la política (como, para él, la cosmética simula ser la gimnástica). Lo que en el presente vivimos rebasa esa noción del simulacro que ahora luce simple. Ocurre que en ese simulacro lo que se intenta simular es, en 
el lenguaje, lo mismo que la actitud racional busca des-encubrir, desocultar. Se puede decir que la actitud retórica, de la antigua retórica, y su contra-actitud racional, la de la filosofía, mantienen el cuidado, el respeto, de aquello por lo que disputan; aquello que está expresado en el lenguaje y sobre lo que se busca mejor comprensión ya sea sólo para el entendimiento - también para la vida pragmática. Ciertamente, mientras la retórica busca ocultarlo queriendo dar brillo deslumbrante a la mera palabra, la actitud filosófica pretende la belleza lógica del lenguaje comprometido con desnudar la verdad de lo que el lenguaje busca decir. El deslumbre de la retórica, con su encandilamiento, encauza el pensamiento entre las márgenes de la manipulación propia de la opinión, de la doxa. Pero, decíamos, en nuestro tiempo se trata no sólo de una nueva retórica sino algo más. Veamos.

En primer lugar, sobre la nueva retórica, sus rasgos fundamentales. Una nueva retórica es lo que se ha caracterizado como el trastrocamiento del lenguaje, en su rigurosidad lógica, para ponerlo al servicio de la ideología o del adoctrinamiento, en el dominio de la política, y, en el dominio de la economía, del abuso de la significación de la palabra para ponerla al servicio de la concentración del poder económico por la vía del mercadeo y la publicidad. De esa caracterización del trastrocamiento del lenguaje hay muy concienzudos análisis que desde mediados del siglo pasado han ido profundizando en la comprensión de la estructuración y funcionalidad. Quizás no resulte abusivo afirmar que estas dos cosas resumen lo esencial al respecto: 1) hacer decir a la palabra lo que no es su decir; en especial, hacerle decir lo contrario de lo que dice, 2) hacer de la palabra un recipiente donde quepan ideas disparatadas, convertirlas en plastikwörter, puestas al servicio de un discurso con definida intencionalidad. Lo esencial de la nueva retórica es que permite el abandono, el olvido, del objeto del discurso, el olvido de aquello de lo que se busca decir algo. En ese sentido, como camino al vaciado del discurso, es un simulacro del simulacro que ya es la retórica; por así decirlo, es un simulacro de segundo orden. En cuanto más vacuo se formula el discurso más generalizado se presenta; vale decir, más aplicable a cualquier dominio de la experiencia humana para decir algo volátil, algo que no dura, algo sobre lo que importa un bledo el carácter de verdad. Sin duda, el foco de resistencia a ese maltrato de la palabra ya no es tanto la filosofía como sí lo es la poesía. Lo asombroso, entonces, del simulacro del simulacro es que logró un predominio que los sofistas y retóricos no alcanzaron a soñar; inundó todos los espacios de todos los conjuntos sociales. Ahora bien, lo que deseamos postular es que, en ese camino de trastrocamiento se ha dado paso a un desbordado empobrecimiento del lenguaje.

Y eso es lo que postulamos como fondo último de la constelación neoliberal. Es el punto ciego de la mirada conjunta. Más ciego al respecto, el ojo derecho que el ojo izquierdo. La mirada de la derecha se encuentra obnubilada con su apropiación de la palabra vacía y volátil al dominio del uso utilitario, y por igual, de las cosas y de los semejantes. En su ceguera, 
DÁVILA, J.

ceguera que consiste en no ver más que a sí misma, lo único que atina a responder ante la crítica que ya se la hecho no es, y no puede ser, más que la soberbia y la arrogancia en sus formas extremas. Menos ciega al respecto, la mirada del ojo izquierdo. Esta ha logrado desbrozar el camino crítico que le permite el juego dialéctico de la mirada conjunta en la medida en que se lo ha podido apropiar. Así, no ciega, sino más bien apartando la tiniebla, ha construido el esfuerzo por desnudar la nueva retórica, por mostrar la mecánica o interpretar el sentido del simulacro del simulacro. Un asunto incomprensible para la mirada del ojo derecho; intolerancia sempiterna de la derecha. Pero, ahora, la tiniebla se ha vuelto más oscura. No sólo se ha vuelto tal sino que ha envuelto hasta la misma crítica. Y es que el lenguaje ha sido puesto en el camino de su aniquilación. No nos referimos a todo el lenguaje en su utilidad, en su funcionalidad, en sus usos, en sus juegos. Nos referimos a lo que podemos llamar el lenguaje más elemental para la vida humana. Ese lenguaje que, es un supuesto de toda cultura, adquirimos en la infancia. El lenguaje del que la educación básica debe ocuparse de enraizar en la cotidianidad del infante. Aniquilar ese lenguaje es la misión no explícita, ciega para ella misma, de la constelación neoliberal. Ese lenguaje, ya en vía de aniquilación, es el lenguaje con el que, en nuestro presente, los docentes de la educación de los niños y jóvenes se enfrentan en la cotidianidad escolar y desde el que los aprendices de la palabra no logran entender nada de cuanto se les quiere enseñar.

Nuestra respuesta entonces a la pregunta de para qué se educa en la sociedad neoliberal: para destruir, para arrasar con la condición humana desde su raíz cultural más elemental. Un descomunal peligro, sin duda. Y frente a él, ¿Qué hacer? Respuesta, quizás abrumadoramente sencilla: dedicar la educación básica a la enseñanza práctica de sólo estas pocas cosas que toda tradición cultural nos ha enseñado: leer, escribir, contar (cuentos y números), hacer música y arte, todo ello bajo la impronta del riguroso ejercicio de la lógica. Pero, seguramente, no es sólo con los niños -y con los jóvenes- que urge hacerlo; al tiempo, o antes, hay que hacerlo con los mismos maestros.

Artigo recebido em: 07/11/2019

Aprovado para publicação em: 27/01/2020

\section{PARA QUE SE EDUCA NA SOCIEDADE NEOLIBERAL?}

RESUMO: Procura-se responder à questão do título através de várias maneiras de entender o que é a educação em uma sociedade neoliberal. Em seguida, é postulada a hipótese do significado absolutamente destrutivo do neoliberalismo em relação à linguagem em sua forma mais elementar. Disso sugere-se o significado de uma resposta diante do perigo de ver realizada plenamente a aniquilação da linguagem mais elementar.

PALAVRAS-CHAVE: Interpretação. Linguagem básica. Competição. Alienação. Educação básica. 


\section{WHY IS EDUCATED IN NEOLIBERAL SOCIETY}

ABSTRACT: We seek to answer the question of the title through various ways of understanding what education is in a neoliberal society. Next, the hypothesis of the absolutely destructive meaning of neoliberalism in relation to language in its most elementary form is postulated. Therefore, the meaning of a response to the danger of seeing the annihilation of the most elementary language fully realized is suggested.

KEYWORDS: Interpretation. Basic language. Competence. Alienation. Basic education.

Jorge DÁVILA: Doutor en Ciências Sociais pela École de Hautes Études en Sciences Sociales. Pesquisador do Centro de Sistemología Interpretativa, Universidad de Los Andes, Mérida, Venezuela.

Orcid: https://orcid.org/0000-0002-2773-4851

E-mail: jl.davilar@smail.com

Este periódico utiliza a licença Creative Commons Attribution 3.0, para periódicos de acesso aberto (Open Archives Iniciative - OAI). 